\title{
Analisis Pengaruh Kompensasi dengan Konsep 3P terhadap Kepuasan Kerja Karyawan (Studi Kasus Hotel Pariwisata Selabintana, Sukabumi)
}

\author{
Novi Maulani \\ Alumni Departemen Manajemen, Fakultas Ekonomi dan Manajemen \\ Institut Pertanian Bogor \\ Erlin Trisyulianti \\ Departemen Manajemen, Fakultas Ekonomi dan Manajemen \\ Institut Pertanian Bogor \\ Email: erlinatr@ipb.ac.id
}

\begin{abstract}
Each company that was ready to compete must have an effective management. Employee's satisfaction depend on their expectation about what will they get from their compensation. The employees is one of the factors that influence the company's progress in the Tourism hotel of Selabintana. One of the main employees's work dissatisfaction factors is compensation that was not in accordance with employee's expectation. The aim of this research is to analyze the influence of compensation with the concept 3P towards the employee's job satisfaction, to identify the level of the employee's job satisfaction, and to analyze gender relations, the age, the level of education, the length of service, and the number of securities of the family towards the employee's job satisfaction of the Tourism hotel of Selabintana Sukabumi. The data collection used the primary data and the secondary data. The testing of the questionnaire was carried out with the validity test used Pearson product moment and the test reliability used the Alpha Cronbach technique, as well as data processing used the analysis method of the factor, cross tabulation and chi square with SPSS version 15.0 for Windows. The analysis factor's result that the most influence factor is Pay for Performance factor. The most influence attribute from the factor of Pay for Position is the salary. The most influence attribute from the factor of Pay for Performance is the rotation of the employee. The most influence attribute from the factor of Pay for Competence was the experience. Based on the calculation, the employees generally is in the satisfied category with the value $63.33 \%$.

Keywords: Compensation, Concept $3 p$.
\end{abstract}

\section{Pendahuluan}

Perusahaan yang siap untuk berkompetisi harus memiliki manajemen yang efektif dalam meningkatkan kinerja karyawan. Dalam hal ini diperlukan dukungan karyawan yang cakap dan kompeten di bidangnya. Di sisi lain, pembinaan karyawan merupakan hal yang harus diutamakan sebagai aset perusahaan, karena karyawan sebagai 
sumberdaya manusia memiliki peranan penting dalam menentukan keberhasilan dan pencapaian tujuan perusahaan (Wahyuddin, 2005).

Rasa kepuasan karyawan dalam perusahaan akan berpengaruh terhadap prestasi kerja karyawan. Pada dasarnya prestasi kerja berkaitan dengan perilaku atau tindakan para karyawannya. Setiap karyawan mempunyai watak dan perilaku yang berbeda, hal tersebut disebabkan karena beberapa faktor, misalnya latar belakang pendidikan, keterampilan, watak dasar maupun faktor lainnya dari karyawan itu sendiri (Panjta, et al., 2003).

Pentingnya suatu kompensasi sebagai salah satu indikator kepuasan dalam bekerja sulit ditaksir karena pandangan-pandangan karyawan mengenai uang atau imbalan langsung nampaknya sangat subyektif (Frasser, 1992), tetapi pada dasarnya adanya dugaan ketidakadilan dalam memberikan upah maupun gaji merupakan sumber ketidakpuasan karyawan terhadap kompensasi (Strauss dan Sayles, 1990).

Hotel Pariwisata Selabintana merupakan hotel pertama yang didirikan di kawasan Selabintana Sukabumi. Karyawan merupakan sumberdaya yang penting dalam menjalankan aktivitas perusahaan yang selalu dituntut untuk meningkatkan kinerjanya dalam upaya pencapaian tujuan perusahaan.

Penelitian ini akan membahas tentang pengaruh kompensasi dengan konsep 3P terhadap kepuasan kerja karyawan di Hotel Pariwisata Selabintana yang mengidentifikasi pengaruh yang ada berdasarkan teori dengan pengaruh yang ada pada Hotel Pariwisata Selabintana berdasarkan penilaian responden (karyawan), sehingga diharapkan dapat mengetahui dengan tepat pengaruh kompensasi dengan konsep 3P terhadap kepuasan kerja karyawan pada Hotel Pariwisata Selabintana.

Kelangsungan suatu perusahaan sangat ditentukan oleh sumberdaya manusia yang ada, baik kualitas maupun kuantitasnya.

Hasil penelitian yang dilakukan oleh para ahli perilaku menunjukkan bahwa salah satu factor ketidakpuasan kerja karyawan adalah kompensasi yang tidak sesuai dengan harapan karyawan. Kondisi ini menuntut perusahaan untuk mengembangkan performanya, yang juga harus didukung oleh karyawan yang professional dan memiliki loyalitas serta dedikasi yang tinggi.

Berdasarkan uraian di atas, maka dapat dirumuskan masalah-masalah sebagai berikut:

1. Bagaimana pengaruh kompensasi dengan konsep 3P terhadap kepuasan kerja karyawan Hotel Pariwisata Selabintana?

2. Bagaimana tingkat kepuasan kerja karyawan Hotel Pariwisata Selabintana?

3. Bagaimana hubungan jenis kelamin, umur, tingkat pendidikan, masa kerja dan jumlah tanggungan keluarga terhadap kepuasan kerja karyawan Hotel Pariwisata Selabintana?

Tujuan Penelitian adalah:

1. Menganalisa pengaruh kompensasi dengan konsep 3P terhadap kepuasan kerja karyawan Hotel Pariwisata Selabintana.

2. Mengidentifikasi tingkat kepuasan kerja karyawan Hotel Pariwisata Selabintana.

3. Menganalisa hubungan jenis kelamin, umur, tingkat pendidikan, masa kerja dan jumlah tanggungan keluarga terhadap kepuasan kerja karyawan Hotel Pariwisata Selabintana. 


\section{Metode Penelitian}

Sumberdaya manusia merupakan salah satu faktor yang berperan penting dalam menentukan berhasil atau tidaknya suatu perusahaan. Peranan dari para karyawan adalah melakukan semua pekerjaan sesuai dengan tugas dan fungsi masing-masing. Akan tetapi dalam pelaksanaannya tidak semua karyawan mempunyai pemahaman yang sama mengenai tugasnya. Hal ini erat kaitannya dengan sikap, nilai, perilaku dan motivasi yang bersangkutan dengan pekerjaan dibebankan kepadanya.

Penelitian ini dilaksanakan di Hotel Pariwisata Selabintana yang berlokasi di Jalan Selabintana Km.7 Sukabumi. Penelitian dilaksanakan selama tiga bulan, mulai bulan Februari sampai bulan April 2009.

Data yang diperlukan dalam peneliatian ini adalah data kualitatif maupun data kuantitatif, baik data primer maupun data sekunder.

a. Data Primer

Data primer merupakan data yang diperoleh secara langsung dari pihak perusahaan dari hasil wawancara dan kuesioner yang disebar kepada 90 responden.

b. Data sekunder

Data sekunder merupakan data penunjang yang diperlukan dalam penelitian ini. Data sekunder ini diperoleh secara tidak langsung dari literatur seperti profil perusahaan yang meliputi visi, misi, tujuan, sejarah, struktur organisasi, serta studi literatur lainnya.

Metode yang digunakan dalam pengambilan data dalam penelitian ini adalah teknik sensus. Uji validitas diperlukan untuk mendapatkan pertanyaan yang valid yang disampaikan kepada para responden. Reliabilitas merupakan derajat ketepatan, ketelitian atau keakuratan yang ditunjukan oleh instrument pengukuran (Umar, 2003).

Tabel 1. Klasifikasi Nilai Alpha

\begin{tabular}{cl}
\hline Klasifikasi & Kesimpulan \\
Nilai Alpha & Sempurna (excellent) \\
$\alpha>0,9$ & Baik (good) \\
$\alpha>0,8$ & Dapat diterima (acceptable) \\
$\alpha>0,7$ & Diragukan (questionable) \\
$\alpha>0,6$ & Lemah (poor) \\
$\alpha>0,5$ & Tidak dapat diterima (unacceptable) \\
$\alpha>0,4$ & \\
\hline
\end{tabular}




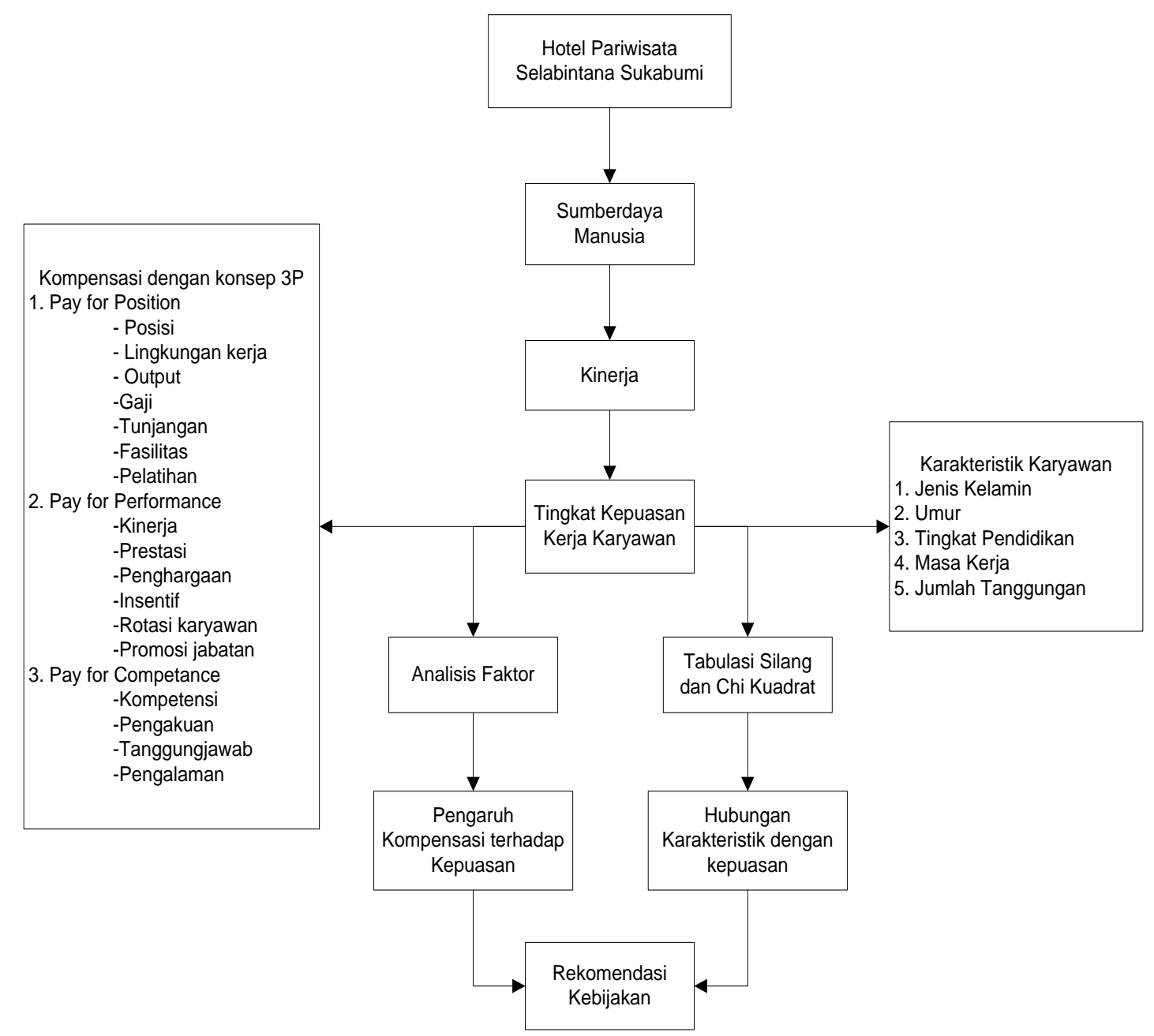

Gambar 1. Kerangka Pemikiran Penelitian

Analisis faktor merupakan serangkaian prosedur yang digunakan untuk mereduksi dan menyimpulkan suatu data (Barus, 2008). Proses analisis faktor mencoba menemukan hubungan antara sejumlah peubah yang saling bebas satu dengan yang lainnya, sehingga dapat dibuat satu atau beberapa kumpulan peubah yang lebih sedikit dari jumlah awal. Penganalisisan faktor menggunakan KMO dan Bartlett of sphericity serta Anti image (Santoso, 2002).

Pengujian kesesuaian analisis faktor dilakukan dengan metode Kaiser-Meyer- Olkin (KMO). Tingkat kesesuaian harga KMO menurut Kaiser dalam Barus (2008) dijelaskan pada Tabel 2.

Tabel 2. Tingkat kesesuaian harga KMO dengan penggunaan analisis faktor

\begin{tabular}{ll}
\hline Harga KMO & Tingkat kesesuaian Penggunaan analisis factor \\
\hline 0,9 & Sangat memuaskan \\
0,8 & Memuaskan \\
0,7 & Harga menengah \\
0,6 & Cukup \\
0,5 & Kurang memuaskan \\
$<0,5$ & Tidak dapat diterima \\
\hline \multicolumn{2}{l}{ Sumber: George dan Mallery (2003). }
\end{tabular}


Uji Chi kuadrat bertujuan untuk menentukan apakah hubungan diantara kedua variable dalam tabulasi silang signifikan atau tidak signifikan secara statistik. Rumus Chi Kuadrat yang digunakan adalah sebagai berikut (Sugiyono, 2004):

Dimana :

$$
\chi^{2}=\sum_{i=1}^{k}\left\{\frac{\left(o_{i j}-E_{i j}\right)^{2}}{E_{i j}}\right\}
$$

$$
\begin{array}{ll}
x^{2} & =\text { Chi Kuadrat } \\
x^{2} a_{i j} & =\text { Nilai yang diobservasi } \\
E_{i j} & =\text { Nilai yang diharapkan }
\end{array}
$$

\section{Hasil Penelitian}

Hotel Pariwisata Selabintana merupakan hotel pertama yang didirikan di kawasan Selabintana Sukabumi. Pada tahun 1941 bernama "Grand Hotel Selabintana" yang dikelola oleh Cos Dekker, seorang berkebangsaan Belanda.

Pada tahun 1942, Jepang mengambil alih pengelolaan Grand Hotel Selabintana. Pengelola saat itu bernama Kagura, pengelolaannya berlangsung hingga tahun 1944. Bangunan hotel baru direnovasi pada tahun 1967 oleh seorang perwira tinggi TNI Angkatan Udara bernama Wiriadinata dari Bandung, dan sejak tahun 1967 hotel ini mulai beroperasi untuk umum.

Hotel ini didirikan atas dasar akta Notaris Raden Mas Suryo di Jakarta dengan surat keputusan No. 77 tanggal 6 Maret 1953 dengan nama PT Perusahaan Dagang Selabintana, dan sejak saat itu nama hotel berubah menjadi Hotel Pariwisata Selabintana. Visinya menjadikan Hotel Selabintana sebagai salah satu hotel wisata pilihan di Sukabumi yang mengedepankan kualitas pelayanan melalui peningkatan mutu pelayanan, fasilitas hotel, dan sarana rekreasi yang aspiratif. Misinya sebagai berikut:

1. Meningkatkan sumberdaya manusia hotel Pariwisata Selabintana.

2. Meningkatkan promosi dan pariwisata hotel Pariwisata Selabintana.

3. Meningkatkan sarana dan prasarana hotel Pariwisata Selabintana.

4. Membina dan mengembangkan obyek wisata.

Komisaris merupakan pemilik sebuah perusahaan. Direktur merupakan pemimpin perusahaan yang mengatur sistem perusahaan dan bertanggungjawab terhadap keberlangsungan perusahaan. General Manajer membawahi empat divisi yaitu :

\section{1). S \& M (Sales and Marketing)}

Membawahi satu fungsi yaitu Marketing yang bertugas membuat strategi pemasaran agar pelanggan tertarik untuk menginap di hotel.

\section{2). Operation Manager}

Membawahi beberapa fungsi, yang terdiri dari (a) FO (Front Office), (b) ADM (Administrasi), (c) TU (Tata Usaha), (d) FB (Food and Beverage), dan (e) Housekeeping.

Bagian FO memiliki bawahan yang terdiri dari Kasir FO dan Bellboy. ADM bertugas untuk mencatat dan membukukan keluar masuknya uang. TU bertugas untuk mendata karyawan dan memeriksa daftar kehadiran karyawan. FB bertugas untuk melayani permintaan barang kebutuhan departemen dan menyusun tarif makanan dan minuman yang menunya sudah tersusun. Bagian F\&B terdiri dari (i) Waiter/ 
Waitress, (ii) Supervisor Food \& Beverage, (iii) Chief Koki, (iv) Koki, dan (v) Gudang Food \& Beverage. Housekeeping bertugas untuk melayani permintaan, dan memberikan persetujuan yang berkenaan dengan keuangan pada waktu housekeeping memberikan permintaan pemeliharaan seluruh bagian.

Bagian housekeeping memiliki bawahan yang terdiri dari (i) Chief Housekeeping, (ii) Chief Roomboy, (iii) Roomboy, (iv) Teknisi, (v) Logistik, (vi) Ekstra, (vii) Linen, (viii) Cleaning Service, dan (ix) Gardening.

\section{3). HRD (Human and Resource Development)}

Divisi HRD membawahi beberapa fungsi, yang terdiri dari (a) Personalia, (b) Satpam, dan (c) Sopir. Personalia bertugas untuk meneliti kembali daftar gaji, besarnya uang lembur dan melayani pembayaran lainnya untuk karyawan. Satpam bertugas untuk menjaga keamanan lingkungan hotel, dan Sopir bertugas untuk mengantar tamu ataupun karyawan perusahaan.

\section{4). Accounting Manager}

Membawahi satu fungsi yaitu Accounting yang bertugas untuk membuat laporan keuangan, menerima keluar masuk uang, memeriksa semua pendapatan, dan memberikan persetujuan jika terjadi permintaan untuk kebutuhan.

Berdasarkan perhitungan uji validitas dengan metode Product Moment Pearson, diperoleh kesimpulan bahwa semua instrument pertanyaan yang terdapat dalam kuesioner tersebut valid pada taraf signifikansi $5 \%$.

Berdasarkan hasil perhitungan uji reliabilitas dengan menggunakan bantuan software SPSS 15.0 for Windows terhadap 30 responden diperoleh nilai alpha cronbach sebesar 0,936. Hal ini menunjukkan bahwa kuesioner reliabel secara sempurna.

Berdasarkan kategori jenis kelamin, dapat dikatakan bahwa sebagian besar responden didominasi oleh jenis kelamin pria sebesar $67 \%$, dan wanita sebesar $33 \%$. Dari hasil tersebut terlihat bahwa sebagian besar karyawan yang bekerja pada Hotel Pariwisata Selabintana adalah kaum pria. Hal ini disebabkan karena proporsi kerja lebih banyak membutuhkan tenaga kerja pria.

Berdasarkan status pekerjaan pada Gambar 3, terlihat bahwa semua karyawan yang bekerja di Hotel Pariwisata Selabintana merupakan karyawan tetap (100\%). Hal ini disebabkan karena para karyawan sebagian besar masih memiliki hubungan persaudaraan antara satu dengan yang lainnya, akan tetapi seiring berjalannya waktu, pihak manajemen akan memberlakukan system kerja kontrak sehingga mampu meningkatkan profesionalisme pekerjaan.

Berdasarkan kategori usia, diketahui bahwa karyawan terbagi menjadi empat kelompok yaitu usia antara 20 - 30 tahun, usia antara 30 - 40 tahun, usia antara $40-$ 50 tahun, dan kelompok usia $>50$ tahun. Dari hasil tersebut dapat terlihat bahwa sebagian besar karyawan merupakan pekerja produktif berusia kisaran usia 40 tahun hingga 50 tahun. Hal ini disebabkan karyawan yang berusia tua lebih merasa puas dengan apa yang dicapai dan jauh lebih berpengalaman dibanding karyawan yang berusia muda.

Pendidikan adalah indikator yang mencerminkan kemampuan seseorang untuk dapat menyelesaikan suatu pekerjaan. Berdasarkan data yang diperoleh diketahui bahwa sebagian besar esponden memiliki pendidikan setingkat diploma yaitu sebesar 
42\%. Tenaga diploma banyak dibutuhkan pada posisi yang terspesialis atau pada bidang teknis seperti administrasi, teknisi, logistik, juru masak dan lainnya.

Lama bekerja karyawan pada umumnya menunjukkan tingkat kemampuan dan pengalaman yang dimiliki. Berdasarkan kategori lama bekerja, responden dibagi menjadi beberapa kelompok, yaitu 1 - 5 tahun, 5- 10 tahun, $10-15$ tahun, dan lebih dari 15 tahun. Kelompok responden terbesar berada pada kelompok masa kerja $5-10$ tahun yaitu sebesar 37 persen.

Berdasarkan kategori besarnya penerimaan, responden terbagi menjadi empat kelompok, yaitu kurang dari Rp 500.000, antara Rp 500.000 - Rp 1.000.000, antara Rp 1.000.000 - Rp 2.000.000, dan antara Rp. 2.000.000 - Rp 3.000.000. Kelompok responden terbesar berada pada kelompok penerimaan antara $\mathrm{Rp} 500.000$ - Rp 1.000.000. Sebagian besar karyawan yang memiliki penghasilan pada range tersebut berada pada posisi roomboy dan waiter/waitress.

Berdasarkan kategori jumlah tanggungan keluarga, responden terbagi menjadi tiga kelompok, yaitu 1-2 orang, $3-5$ orang, dan kelompok jumlah tanggungan $6-8$ orang. Kelompok responden terbesar berada pada kelompok jumlah tanggungan 3 5 orang yaitu sebesar 41 persen. Hal ini dikarenakan sebagian besar sudah berusia 40-50 tahun dan telah berkeluarga.

Berdasarkan karakteristik responden menurut tugas, responden terbagi menjadi empat kelompok yaitu Sales \& Marketing (S \& M), Operational (OPR), Human and Resource Development (HRD), dan Accounting (ACT). Kelompok responden terbesar berada pada kelompok OPR yaitu sebesar 84 persen. Dari data tersebut dapat disimpulkan bahwa tenaga OPR lebih banyak dibutuhkan dan sangat mempengaruhi operasional harian hotel.

Karakteristik responden berdasarkan fungsi yang dimiliki terbagi menjadi sepuluh kelompok. Kelompok fungsi terbesar terdapat pada bagian Housekeeping yaitu sebesar 52 persen, hal ini berkaitan dengan semakin besar ukuran hotel maka semakin banyak tenaga operasional yang dibutuhkan.

Dilihat dari karakteristik responden menurut pembagian wewenang, terbagi menjadi dua kelompok yaitu kelompok manajer dan supervisor yang besarnya masingmasing 50 persen. Hal ini dilihat dari kuantitas karyawan yang menduduki posisi tersebut.

Berdasarkan perhitungan analisis faktor dari ketiga faktor yang digunakan untuk mengukur kepuasan kerja karyawan yang terkait dengan kompensasi yang diberikan oleh perusahaan, dapat diketahui bahwa faktor 2 (pay for performance) adalah faktor yang paling berpengaruh terhadap kepuasan kerja karyawan dengan nilai ekstraksi sebesar 0, 914.

Tabel 3. Nilai Ekstraksi Atribut-atribut pada Faktor yang Mempengaruhi Kepuasan Kerja Karyawan

\begin{tabular}{lcc}
\hline & Initial & Extraction \\
\hline Faktor 1 (pay for position) & 1.000 & .825 \\
Faktor 2 (pay for performance) & 1.000 & .914 \\
Faktor 3 (pay for competence) & 1.000 & .779 \\
\hline
\end{tabular}


Dari Tabel 3 dapat dilihat bahwa karyawan lebih merasa puas terhadap faktor kompensasi berdasarkan kinerja (faktor 2) dengan nilai ekstraksi sebesar 0,914 dibanding kedua faktor kompensasi lainnya. Hal tersebut membuktikan bahwa kinerja yang dimiliki seorang karyawan akan sangat mempengaruhi besar kecilnya kompensasi yang akan diberikan oleh pihak perusahaan.

Analisis factor digunakan untuk menganalisis faktor-faktor yang terkait dengan kepuasan kerja karyawan. Metode ini bertujuan untuk menemukan hubungan antara atribut-atribut yang saling bebas satu dengan yang lainnya, sehingga dapat dibuat satu atau beberapa kumpulan atribut yang lebih sedikit dari awal, tetapi tetap mencerminkan atribut aslinya, sehingga pada akhirnya ada pengelompokkan antara atribut yang berkorelasi kuat yang dapat memudahkan pihak perusahaan dalam pemberian kebijakan kompensasi yang sesuai untuk peningkatan kepuasan karyawan.

Penelitian ini, atribut awal yang sudah dianalisis berjumlah delapan belas atribut dari tiga faktor kompensasi, yaitu faktor partama pay for position : (X1) posisi, (X2) Lingkungan kerja, (X3) output, (X4) gaji, (X5) tunjangan, (X6) fasilitas, (X7) pelatihan. Faktor kedua pay for performance: (X1) kinerja, (X2) prestasi, (X3) penghargaan, (X4) insentif, (X5) rotasi karyawan, (X6) promosi jabatan. Faktor ketiga pay for competence: (X1) kompetensi, (X2) pengakuan, (X3) tanggung jawab, (X4) pengalaman, (X5) masa kerja.

Tabel 4 menunjukkan bahwa atribut yang paling mempengaruhi terhadap kepuasan karyawan berdasarkan analisis faktor pada faktor pay for position (faktor 1 ) adalah gaji dengan nilai ektraksi sebesar 0,780.

Tabel 4. Nilai Ekstraksi Atribut-atribut pada Faktor Pay for Position

\begin{tabular}{lll}
\hline Atribut & Initial & extraction \\
\hline Posisi (A1) & 1.000 & .181 \\
Output(A3) & 1.000 & .503 \\
Gaji (A4) & 1.000 & .780 \\
Tunjangan (A5) & 1.000 & .622 \\
Pelatihan (A7) & 1.000 & .561 \\
\hline
\end{tabular}

Dari Tabel 4 dapat terlihat bahwa atribut pay for position yang paling mempengaruhi terhadap kepuasan kerja karyawan adalah gaji, hal ini membuktikan bahwa besarnya gaji yang diberikan oleh pihak perusahaan sudah dirasakan cukup memuaskan bagi sebagian karyawan.

Atribut-atribut faktor kedua yang paling memuaskan karyawan berdasarkan hasil pengolahan data adalah rotasi karyawan dengan nilai ektraksi sebesar 0,760 . Menurut karyawan atribut ini adalah yang sangat mempengaruhi dengan nilai ektraksi sebesar 0,760 . Hal ini dimaksudkan untuk mengurangi tingkat kejenuhan, menambah kemampuan karyawan, dan pengetahuan tentang bagian-bagian organisasi yang berbeda agar tidak hanya ahli dalam satu bidang saja. 
Tabel 5. NIlai Ekstraksi Atribut-atribut pada Faktor Pay for Performance

\begin{tabular}{llc}
\hline & Initial & Extraction \\
\hline Kinerja & 1.000 & .568 \\
Prestasi & 1.000 & .456 \\
Penghargaan & 1.000 & .730 \\
Insentif & 1.000 & .514 \\
Rotasi karyawan & 1.000 & .760 \\
Promosi jabatan & 1.000 & .516 \\
\hline
\end{tabular}

Kompetensi dibutuhkan oleh seorang karyawan, karena hal tersebut merupakan salah satu faktor yang menjadi pertimbangan sebuah perusahaan. Berdasarkan hasil perhitungan analisis faktor, diperoleh atribut yang memuaskan karyawan yaitu pengalaman dengan nilai ekstraksi sebesar 0,709. Menurut para karyawan faktor tersebut menjadi hal yang sangat mempengaruhi terhadap kepuasan kerja karena semakin banyak pengalaman bekerja yang dimiliki semakin dapat meningkatkan kompensasi finansial karena kecakapan serta keterampilannya lebih baik.

Tabel 6. Nilai Ekstraksi Atribut-atribut pada Faktor Pay for Competence

\begin{tabular}{lcc}
\hline & Initial & Extraction \\
\hline Kompetensi & 1.000 & .356 \\
Pengakuan & 1.000 & .441 \\
Tanggung jawab & 1.000 & .439 \\
Pengalaman & 1.000 & .709 \\
Masa kerja & 1.000 & .651 \\
\hline
\end{tabular}

Berdasarkan hasil perhitungan pada hasil nilai rataan yang diperoleh dari jawaban karyawan mengenai kepuasan kerjanya, diperoleh nilai rataan sebesar 63,22\%. Dengan melihat nilai tersebut diperoleh kesimpulan bahwa saat ini karyawan secara umum berada pada kategori puas terhadap kompensasi yang diterimanya.

Hasil dari Tabulasi Silang dan Chi Kuadrat digunakan untuk melihat hubungan antara karakteristik responden dengan tingkat kepuasan kerja karyawan.

a) Analisis Atribut Jenis Kelamin terhadap Kepuasan Kerja Karyawan

Berdasarkan analisis terhadap atribut tersebut, jenis kelamin tidak memiliki hubungan dengan kepuasan kerja karyawan. Hal ini terlihat dari nilai Chi Kuadrat hitung $(4,970)$ lebih kecil dari nilai Chi Kuadrat tabel $(7,815)$, maka terima HO artinya tidak terdapat hubungan antara jenis kelamin responden terdapat kepuasan kerja karyawan.

b) Analisis Atribut Usia terhadap Kepuasan Kerja Karyawan

Berdasarkan analisis tabulasi silang terhadap atribut tersebut, karyawan yang berada pada kelompok usia 40 - 50 tahun memiliki jumlah sebanyak 17 orang yang merasa puas. Hasil perhitungan Chi Kuadrat menyatakan karakteristik responden berdasarkan usia memiliki hubungan dengan kepuasan kerja karyawan. Hal ini terlihat dari nilai Chi Kuadrat hitung $(28,554)$ lebih besar dari nilai Chi Kuadrat tabel $(12,592)$, maka terima $\mathrm{H} 1$ yang artinya terdapat hubungan antara usia dengan kepuasan kerja karyawan sebesar 15,962 $(28,554-12,592)$. 
c) Analisis Atribut Tingkat Pendidikan terhadap Kepuasan Kerja Karyawan

Berdasarkan analisis tabulasi silang terhadap atribut tersebut diperoleh jumlah karyawan terbesar pada kelompok diploma yaitu sebanyak 26 orang dengan tingkat kepuasan netral. Dari hasil perhitungan Chi Kuadrat diperoleh nilai Chi Kuadrat hitung $(10,659)$ lebih besar dari nilai Chi Kuadrat tabel $(9,488)$, maka terima $\mathrm{H} 1$ yang artinya terdapat hubungan antara karakteristik responden berdasarkan tingkat pendidikan dengan kepuasan kerja karyawan yang jumlahnya sebesar 1,171 $(10,659-9,488)$.

d) Analisis Atribut Masa Kerja terhadap Kepuasan Kerja Karyawan

Berdasarkan analisis tabulasi silang terhadap atribut tersebut diperoleh jumlah karyawan terbesar sebanyak 20 orang pada kelompok masa kerja $5-10$ tahun dengan tingkat kepuasan nertal, diikuti dengan kelompok masa kerja 1 - 5 tahun dan $10-15$ tahun yang masing-masing berjumlah 14 orang dengan tingkat kepuasan kerja netral dan puas. Dari hasil perhitungan Chi Kuadrat diperoleh nilai Chi Kuadrat hitung sebesar 17,369 yang lebih besar dibanding nilai Chi Kuadrat tabel 12,592. Maka terima H1 yang artinya terhadap hubungan antara masa kerja dengan tingkat kepuasan kerja karyawan sebesar 4,777 (17,369-12,592).

e) Analisis Atribut Jumlah Tanggungan Keluarga terhadap Kepuasan kerja Karyawan

Berdasarkan hasil analisis tabulasi silang terhadap atribut tersebut, diketahui jumlah karyawan pada kelompok tanggungan keluarga 3-5 orang dan kelompok tanggungan $6-8$ orang sebanyak 18 orang dengan masing-masing tingkat kepuasan netral dan puas. Dari hasil perhitungan Chi Kuadrat diperoleh nilai Chi Kuadrat hitung 10,628 yang lebih besar dari nilai Chi Kuadrat tabel 9,488. Maka terima H1 yang artinya terdapat hubungan antara karakteristik responden berdasarkan jumlah tanggungan keluarga dengan kepuasan kerja karyawan sebesar 1,14 (10,628-9,488).

\section{Kesimpulan}

Faktor pay for performance merupakan faktor kompensasi yang paling berpengaruh terhadap kepuasan kerja karyawan dibanding faktor pay for position dan pay for competence. Pada faktor pay for position (faktor 1) gaji merupakan atribut yang paling mempengaruhi terhadap kepuasan kerja karyawan. Pada faktor pay for performance (faktor 2) rotasi karyawan merupakan atribut yang paling mempengaruhi diantara atribut lainnya. Pada faktor pay for competence (faktor 3) pengalaman merupakan faktor yang paling mempengaruhi kepuasan kerja karyawan.

Tingkat kepuasan kerja karyawan Hotel Pariwisata Selabintana secara umum berada pada kategori puas terhadap kompensasi yang diterimanya.Terdapat empat atribut karakteristik responden yang mempunyai hubungan dengan tingkat kepuasan kerja karyawan yaitu usia, tingkat pendidikan, masa kerja, dan jumlah tanggungan keluarga. Karakteristik responden berdasarkan usia memiliki hubungan yang paling tinggi. Sedangkan karakteristik responden yang memiliki hubungan terkecil adalah jumlah tanggungan keluarga.

\section{Daftar Pustaka}

Barus, E.F.S. 2008. Analisis Preferensi Calon Konsumen Terhadap Atribut Jasa Program Sarjana Penyelenggaraan Khusus (Studi Kasus Program Diploma di 
Kotamadya Bogor). Skripsi pada Fakultas Ekonomi dan Manajemen, Institut Pertanian Bogor, Bogor.

Fraser, T.M. 1992. Stress dan Kepuasan Kerja, Seri Manajemen No. 14. Pustaka Binaan Pressindo, Jakarta

George, D. dan Mallery. 2003. SPSS for Windows steps by steps : A Simple Guide and Reference 11.0 Update. Allyn and Bacon, Boston.

Pantja, et al. Maret 2003. Kajian Terhadap Kepuasan Kompensasi, Kominmen Organisasi dan Prestasi Kerja. Jurnal Manajemen \& Kewirausahaan Vol. 5, No. 1. Jurusan Ekonomi Manajemen, Fakultas Ekonomi - Universitas Kristen Petra Surabaya, Surabaya.

Santoso. 2002. Mengatasi berbagai Masalah Statistik dengan SPSS Versi 13. Elek Media Komputindo, Jakarta.

Strauss, George, dan Leonardo Sayler. 1990. Manajemen Personalia: Segi Manusia dalam Organisasi. Pustaka Binaan Pressindo, Jakarta.

Sugiyono. 2004. Statistik untuk Penelitian. Alfabeta, Bandung.

Umar, H. 2003. Riset Sumberdaya Manusia dalam Organisasi. PT Gramedia Pustaka Utama, Jakarta.

Wahyuddin, P. 2005. Pengaruh Faktor-faktor Kepuasan Kerja terhadap Kinerja Karyawan Pusat Pendidikan Akutansi IMKA di Surakarta. Jurnal BENEFIT. Program Pascasarjana Fakultas Ekonomi, UMS Surakarta. 